\title{
RISK-BASED LIFE CYCLE MIM STRATEGY FOR COASTAL STRUCTURES - EFFECT OF PRE-EXISTING DAMAGES ON FAILURE PROBABILITY -
}

\author{
Nannina Horstmann ${ }^{1}$, Kerstin Hinze ${ }^{2}$, Stefan Schimmels ${ }^{3}$, Hocine Oumeraci ${ }^{4}$ \\ A risk-based strategy for monitoring, inspection and maintenance (MIM) is described as a key component of an \\ overall framework for life-cycle engineering and management. Its application for coastal structures is exemplarily \\ outlined for sea/estuary dikes and harbor quay walls. The necessity of the incorporation of pre-existing damages into \\ this strategy is exemplarily illustrated for quay walls, showing how this will affect the failure probability in \\ comparison to a quay wall without any pre-existing damages.
}

Keywords: Sea and estuary dikes; weak spots; initial damages; failure probability; fault tree analysis

\section{INTRODUCTION}

The challenges associated with the sustainable design of coastal structures and the considerable uncertainties associated with climate changes und socio-economic developments necessarily require robustness and flexibility over the entire structure life time. Therefore, in the framework of a joint research project on life cycle engineering between Leibniz Universität Hannover (LUH) and Technische Universität Braunschweig (TU BS), Germany, a reliability and risk-based strategy is developed for monitoring, inspection and maintenance (MIM strategy) for coastal structures. This strategy constitutes a core component of an overall framework for life cycle engineering and management to reduce life cycle costs complying with sustainable principles. The new MIM strategy is outlined and illustrated using typical examples of coastal structures such as sea and estuary dikes as well as quay walls.

First, a scientific basis for an improved understanding of the degradation mechanisms and their effects on failure probability and serviceability of the aforementioned structures has to be established. Based on the gained knowledge, the methods, models and techniques are developed, which are required to fully implement the MIM strategy in engineering practice. As the MIM strategy is risk-based, the prospective methods and models account explicitly for the associated uncertainties (probabilistic approaches) and failure consequences (risk analysis) and include Bayesian updating techniques.

This paper briefly describes the MIM strategy with a particular focus on the methodology to integrate pre-existing damages of sea and estuary dikes as well as of quay walls to the approach and how these will affect the failure probability of the structures in comparison to those without any preexisting damages. An example application is provided to illustrate the effect of a detected initial damage on the failure probability of a quay wall.

\section{THEORETICAL BACKGROUND}

\section{General design and failure mechanism of sea and estuary dikes}

Reliability and risk analyses are performed for a typical dike profile at the German North Sea which generally consists of a grass cover, clay layer and a sand core as can be seen in Figure 1. In order to allocate failure mechanisms to different locations of the dike cross section, the dike profile is divided into three parts: (i) seaward slope, (ii) dike core and (iii) landward slope.

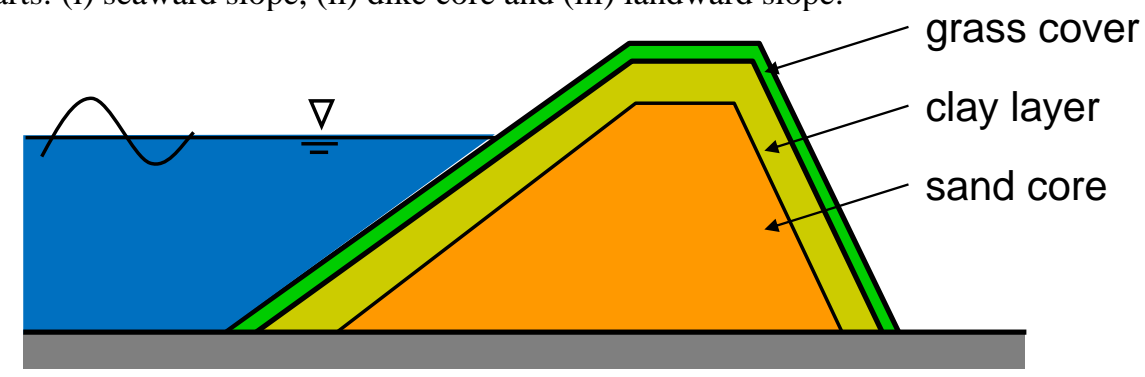

Figure 1. Principle sketch of a sea dike at the German North Sea.

1 Forschungszentrum Küste (FZK), Hannover. Since Sept. 2012: Franzius-Institut für Wasserbau und Küsteningenieurwesen, Leibniz Universität Hannover, Nienburger Straße 4, Hannover, 30167, Germany

${ }^{2}$ Leichtweiß-Institut, Technische Universität Braunschweig, Beethovenstraße 51a, Braunschweig, 38106, Germany

${ }^{3}$ Forschungszentrum Küste (FZK), Hannover, Merkurstraße 11, Hannover, 30419, Germany

${ }^{4}$ Leichtweiß-Institut, Technische Universität Braunschweig, Beethovenstraße 51a, Braunschweig, 38106, Germany 
Naulin et al. (2012) suggested that hydrodynamic processes can be divided for the seaward slope in (i) breaking wave impact, (ii) wave run-up and run-down as well as (iii) breach inflow. The dike core is mostly affected by (i) infiltration of water and (ii) breach flow and the hydrodynamic processes on the landward slope can be classified as (i) wave overtopping and overflow and (ii) breach flow.

Due to these hydrodynamic influences several morphodynamic and geotechnical processes can occur which are given in Table 1.

\begin{tabular}{|c|c|c|}
\hline Seaward slope & Dike core & Landward slope \\
\hline BREACH INITIATION & BREACH INITIATION & BREACH INITIATION \\
\hline Grass cover failure & Seepage & Grass cover failure \\
\hline \multirow[t]{4}{*}{ Clay layer failure } & Suffusion & Clay layer failure \\
\hline & Sliding & Macro instability \\
\hline & Piping (internal erosion) & Micro instability \\
\hline & & Cap failure \\
\hline BREACH FORMATION & & BREACH FORMATION \\
\hline Wash-out of sand core & & Wash-out of sand core \\
\hline BREACH DEVELOPMENT & & BREACH DEVELOPMENT \\
\hline Lateral erosion & & Lateral erosion \\
\hline
\end{tabular}

Further information to failure mechanisms of sea dikes are also given in e.g. Allsop et al. (2007).

\section{General design and failure mechanism of quay walls}

Quay wall constructions can be e.g. gravity walls constructed with concrete blocks, but especially at German coast lines with weak soils, anchored sheet pile walls have been developed in the past years. Wall elements of these structures are U-shaped steel profiles connected with bolted on Z-profiles. In Figure 2 a principle sketch of a quay wall is given.

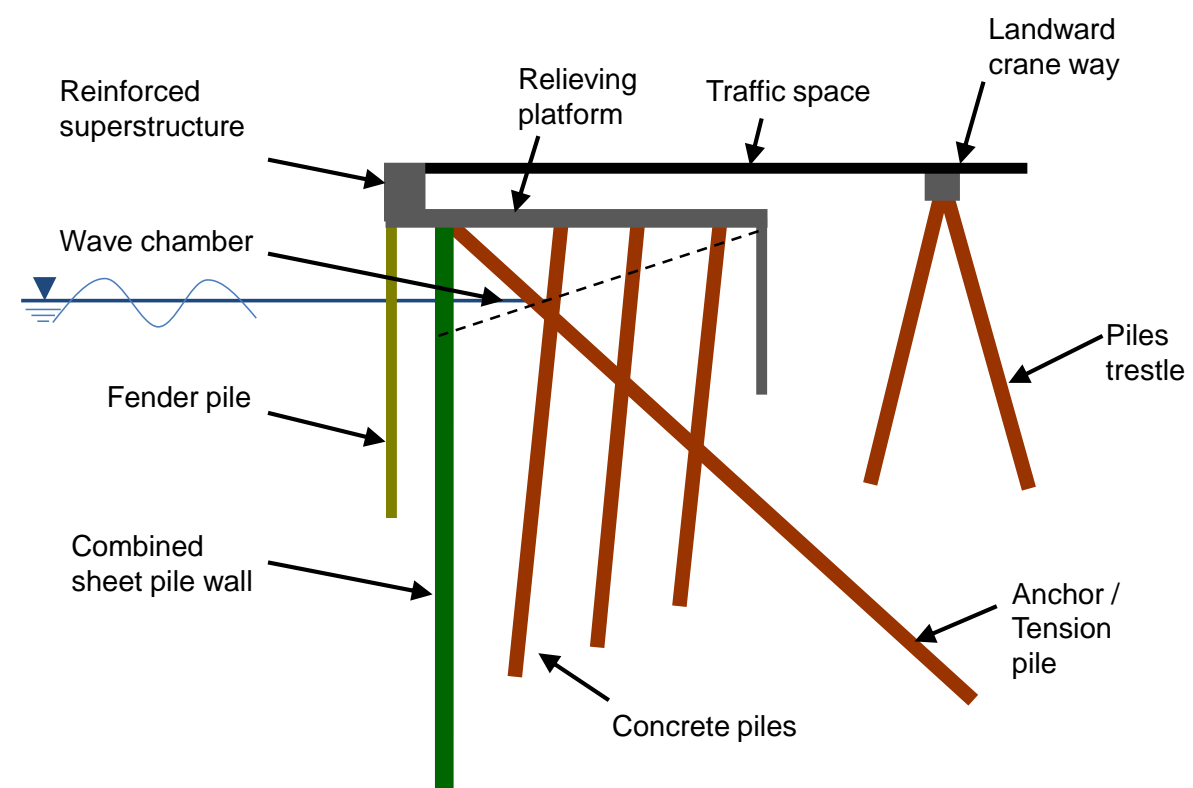

Figure 2. Sheet pile structure representing a typical quay wall construction in German harbors (Principle sketch).

Due to increasing ship sizes and resulting water depths in harbours, sheet pile walls need to be anchored. A compact superstructure placed on the wall and on raked piles ensures the transfer of the crane beam load and all traffic loads directly into the subsoil.

Most failure mechanisms are caused by chloride penetration into the superstructure due to direct contact with sea water which leads to corrosion of the reinforced steel and failure of the concrete. Corrosion of the sheet piles is also a main problem which can lead to a collapse of the entire structure.

Principally, quay walls are not affected by the types of failure leading to a collapse but rather by those resulting in a reduction of serviceability e.g. settlement of the traffic space and crane way or corrosion of fenders and bollards. 


\section{RELIABILITY ANALYSIS}

In the reliability analysis the risk of a failure $R$ is defined as failure probability multiplied by consequences of the damage (e.g. Oumeraci, 2004) as given in Equation 1:

$$
R=P_{f} \cdot E(D)
$$

where $P_{f}=$ failure probability and $E(D)=$ consequences of the damage. In order to perform the reliability analysis of dikes and quay walls the failure mechanisms have to be expressed in limit state equations. By combining them in a fault tree, the failure probability of the top event can be determined. These two key components are described briefly in the following sections.

\section{Limit state equations}

In order to implement and analyse failures mechanisms of dikes in a reliability analysis it is necessary to describe the corresponding limit state equations (LSE) which define the relation between the load applied to the structure and its resistance and strength by the following general Equation 2:

$$
z=R-S
$$

where $R=$ resistance/strength and $S=$ stress/load. Parameter $R$ represents the resistance/strength of the structure and is described as a function of geometrical and/or geotechnical properties of the structure, for dikes e.g. crown height, thickness of the revetment layer, cohesion of the soil and for quay walls e.g. structural properties such as composition of the concrete, strength of the sheet piles or tensions piles. Parameter $S$ represents the load applied to the structure and is described as a function of hydraulic conditions, such as water depth, wave parameters or in the case of a quay wall also the earth pressure. Failure occurs when the loading exceeds the strength of the structure, i.e. $S>R$, and the structure functions when $S \leq R$. Therefore, $z=0$ describes the limit state, i.e. the boundary between non-failure and failure.

Due to the fact, that the methodology of the reliability analysis is based on the calculation of failure probabilities in order to consider uncertainties of load, material and geometry parameters as mentioned before, also $R$ and $S$ in Equation 2 have to random variables given with their probability density function (PDF). The failure probability $P_{f}$ can then be derived by considering the PDFs of the random variables as shown in Figure 3.

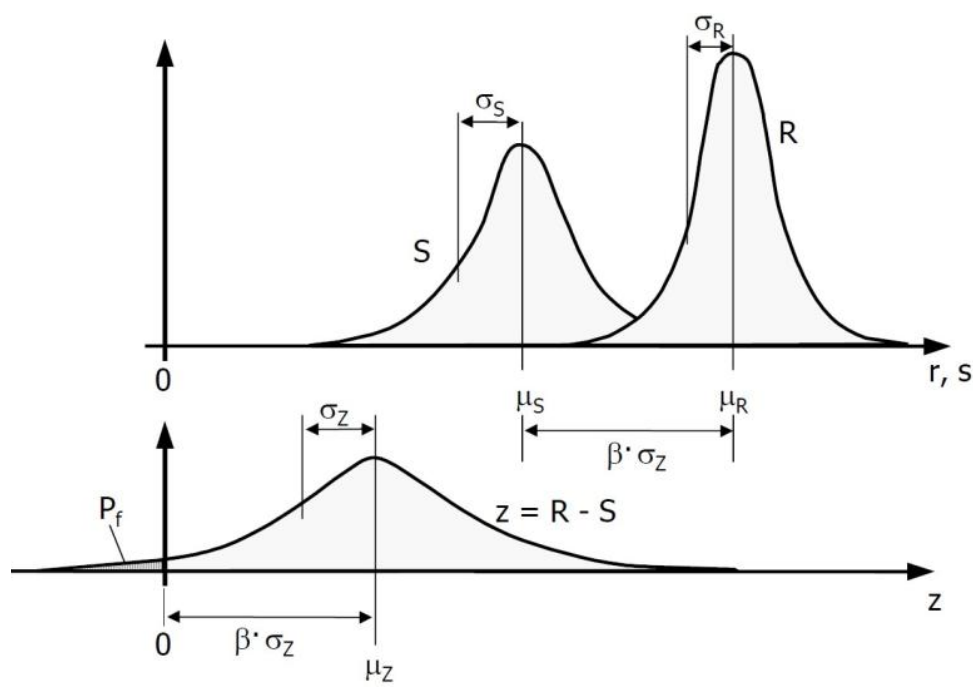

Figure 3. Probability density functions of load (S) and resistance (R) (Kortenhaus, 2003).

In Figure 3 is also given that the distance between the mean values of both PDFs is defined by the reliability index $\beta$ multiplied with the standard deviation $\sigma_{z}$, whereby $\beta$ can be derived as follows:

$$
\beta=\frac{\mu_{x 2}-\mu_{x 1}}{\sqrt{\sigma_{x 1}^{2}+\sigma_{x 2}^{2}}}
$$

where $\mu_{x 1,2}$ are the mean values of stresses (1) and resistance (2) and $\sigma_{x 1,2}$ are the standard deviations of stresses (1) and resistance (2). Consequently, for larger values of $\beta$ the failure probability $P_{f}$ decreases and the structure is more reliable. 
The failure probability $P_{f}$ can then be obtained by the reliability index $\beta$ for normal distributed parameters with the cumulative distribution function (CDF) as given in the following:

$$
P_{f}=\phi(-\beta)
$$

Values of the cumulative distribution function (CDF) are listed in tables such as e.g. in Nowak and Collins (2000).

\section{Fault tree analysis}

In the fault tree analysis, events are connected by OR-gates and AND-gates to calculate the failure probability for a top event. Thus, the aforementioned limit state equations will be used for each individual event, respectively roots of the fault tree, to calculate the failure probability for each event and by multiplying (AND-gate) or adding (OR-gate) these results the failure probability of the top event can be calculated. In Figure 4 a principle sketch of a fault tree is given.

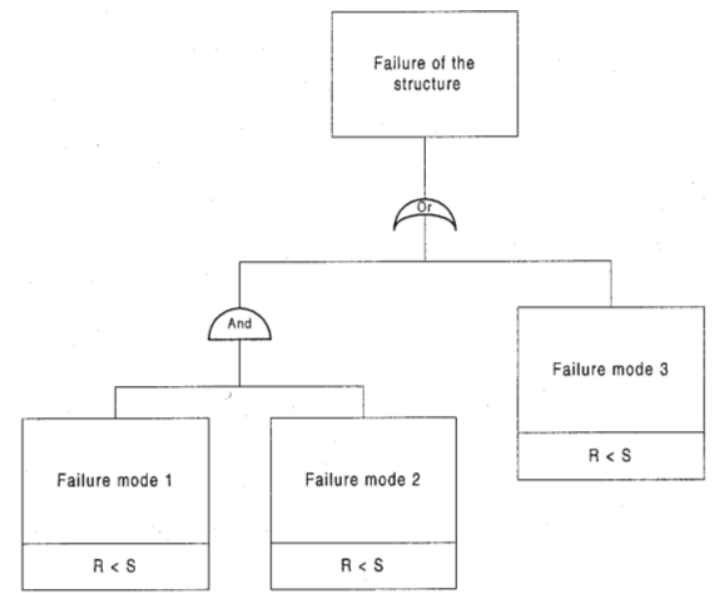

Figure 4. Principle sketch of a fault tree with AND- and OR-Gate (Oumeraci et al., 2001).

For dikes, several simple and also complex fault trees have been collated (e.g. Bakker \& Vrijling (1980), Kortenhaus (2003)). In the literature, fault trees of dikes are usually described only qualitatively and calculated only partially (i.e. not for all documented failure mechanisms) or calculated using simple examples due to their complexity and dependencies between the individual events, whereby influences of duration, sequence and simultaneity of processes are not considered.

In the Dutch guidelines in CUR 166 (1997) a fault tree for quay walls with the top event 'failure of sheet pile wall' is given. This was used as a starting point to present the failure mechanisms for several limit states. CUR (2005) expanded this fault tree for quay walls with relieving structure.

In the German guidelines EAU (2004) an exact fault tree for quay walls is not provided, but the ultimate limit states are divided in three sub-limit states from which a fault tree can be drawn.

Additionally, Allsop et al. (2007) figured out from the FLOODsite project several limit state equations for failure mechanisms of quay walls which can be applied to calculate failure probabilities.

\section{CONSIDERATION OF PRE-EXISTING DAMAGES FOR DIKES AND QUAY WALLS}

Previous studies on pre-existing damages for dikes

Damages for sea and estuary dikes are mainly related to grass erosion due to breaking wave impacts as well as wave run-up and run-down and subsequent erosion of the clay which may result in dike breaching (Stanczak \& Oumeraci, 2012a, b). Seijffert \& Verheij (1998) investigated the response of a grass cover due to impact of breaking waves as well as to wave run-up and run-down. Based on the results of several different tests, they developed an approach to determine the depth of erosion $d_{A}$ for dikes with an outside slope of 1:4 due to breaking wave impact:

$$
d_{A}=C_{E} \cdot H_{s}^{2} \cdot t
$$

where $C_{E}$ is a coefficient related to the quality of the turf and the soil in the sod $\left[\mathrm{m}^{-1} \mathrm{~s}^{-1}\right]$ and values are given by Seijffert \& Verheij (1998) in Table $1, H_{s}$ is the significant wave height [m] and $t$ is the duration of wave impact [s]. It has to be mentioned that this is only a qualitative approach because it is not specified, which are the criteria for a "good", "average" or "poor" grass cover quality. 


\begin{tabular}{|c|c|}
\hline Grass cover quality & $C_{E}\left[\mathrm{~m}^{-1} \mathrm{~s}^{-1}\right]$ \\
\hline Good & $0.5 \cdot 10^{-6}$ to $1.5 \cdot 10^{-6}$ \\
\hline Average & $1.5 \cdot 10^{-6}$ to $2.5 \cdot 10^{-6}$ \\
\hline Poor & $2.5 \cdot 10^{-6}$ to $3.5 \cdot 10^{-6}$ \\
\hline
\end{tabular}

In the European project ComCoast, investigations on overtopping resistance of sea dikes were performed with the overtopping simulator. Akkerman et al. (2007) pointed out that unreinforced grass covers withstand wave overtopping rates of $50 \mathrm{l} / \mathrm{s} / \mathrm{m}$; no major erosion could be noticed although some parts of roots became exposed and lost contact with the subsoil. Therefore, initial damages with dimensions of (i) $1.0 \times 1.0 \mathrm{~m}$ with a depth of $5 \mathrm{~cm}$ and (ii) $0.4 \times 0,4 \mathrm{~m}$ with a depth of $15 \mathrm{~cm}$ were introduced in the grass cover and clay layer of the dike and the test with a maximum overtopping rate of $50 \mathrm{l} / \mathrm{s} / \mathrm{m}$ was repeated. The results of those tests are given in Figure 5.
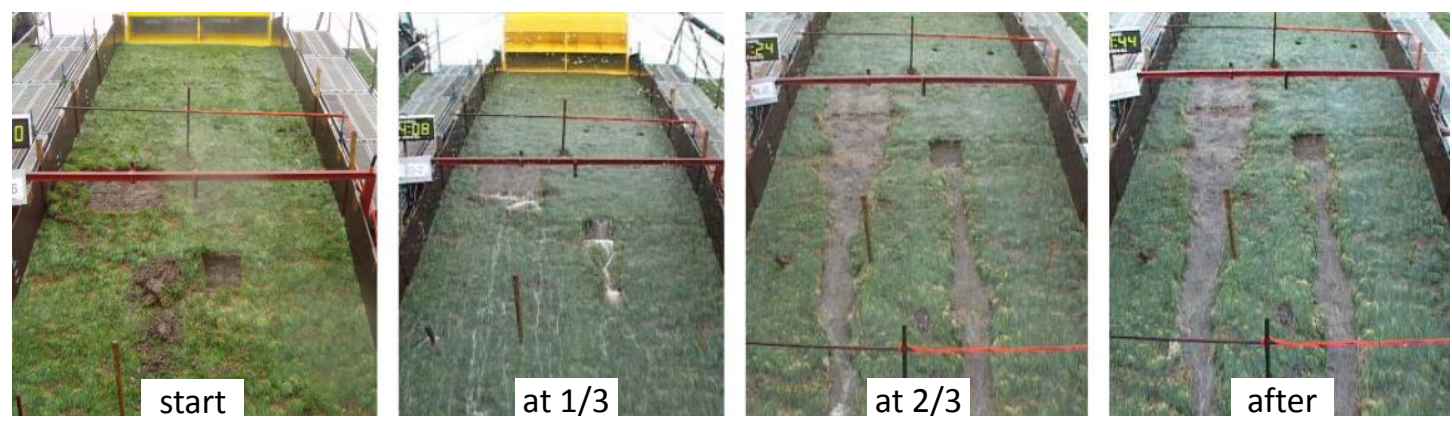

Figure 5. Results of overtopping tests by including initial damages in grass cover and clay layer of the dike (Akkerman et al., 2007).

The pictures in Figure 5 show the most vulnerable area is in the direction of the water flow and that a gully erosion occurs downstream of these spots. The development of the gully formation was mainly concentrated along the length of the slope and less in width and depth. A model for wave overtoppinginduced erosion of grassed inner sea-dike slopes was recently developed by Tuan \& Oumeraci (2012).

An approach for a limit state equation to determine the stress resistance of grass cover to breaking waves is given by Führböter (1966) and developed further by Richwien \& Pohl (2004) and Buß \& Kortenhaus (2008). Figure 6 shows the general structure of grass cover and clay layer and it can be seen that the grass cover is divided in (i) the sward above the turf and (ii) the root network in the turf.
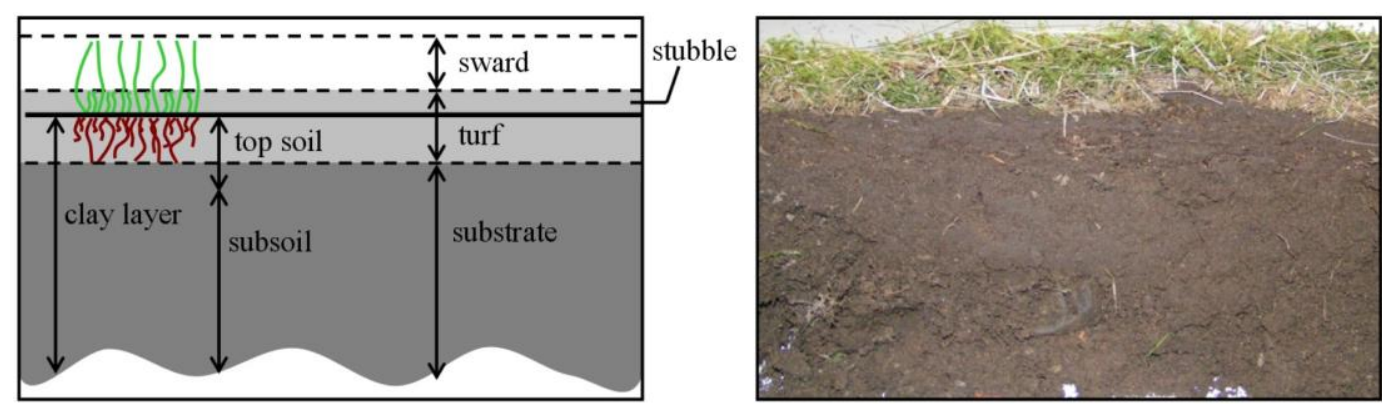

Figure 6: Principle sketch and cross section of grass cover of a sea dike (Stanczak \& Geisenhainer, 2007).

Therefore, Stanczak \& Geisenhainer (2007) suggested that damages of grass cover can be separated into (i) damages of the sward and (ii) damages of the root networks as will be explained in the following:

(i) Damages of the sward:

When the sward is damaged it can be removed completely, but the root network is still present. Temple \& Hanson (1994) pointed out that the effective shear stress $\tau_{0}$ on the surface will be decreased by the presence of intact sward as can be seen from the following equation: 


$$
\tau_{0}=g \cdot \rho_{w} \cdot h \cdot J \cdot\left(1-C_{f}\right) \cdot\left(\frac{n_{s}}{n}\right)^{2}
$$

where $g$ is the gravity acceleration $\left[\mathrm{m} / \mathrm{s}^{2}\right], \rho_{w}$ is the water density $\left[\mathrm{kg} / \mathrm{m}^{3}\right], h$ is the flow depth $[\mathrm{m}]$, $J$ is the slop of energy head line [-], $C_{f}$ is the vegetal cover factor [-], $n_{s}$ is the soil grain roughness $\left[\mathrm{m}^{-1 / 3} \mathrm{~s}\right]$ and $n$ is the total surface roughness $\left[\mathrm{m}^{-1 / 3} \cdot \mathrm{s}\right]$.

Vavrina (2011) suggested that the vegetal cover factor $C_{f}$ can be substituted by the grass cover factor $B$ used by Liebrand (1999). The total surface roughness $n$ can be calculated with the following empirical equation by Temple (1980):

$$
n=e^{0,01329 \cdot C_{I} \cdot\left[\ln \left(R_{v}\right)\right]^{2}-0,09543 \cdot C_{I} \cdot\left[\ln \left(R_{v}\right)\right]+0,2971 \cdot C_{I}-4,16}
$$

where $C_{I}$ is a classification parameter for the grass cover, which is given by SCS (1954) depending on the vegetation class as can be seen in Table $2 ., R_{v}$ is the modified Reynolds number and can be calculated with the following equation:

$$
R_{v}=\left(\frac{v \cdot y}{v}\right) \cdot 10^{-5}
$$

where $v$ is the flow velocity of the water $[\mathrm{m} / \mathrm{s}], y$ is the layer thickness of the flowing water $[\mathrm{m}]$ and $v$ is the viscosity of the water $\left[\mathrm{m}^{2} / \mathrm{s}\right]$.

\begin{tabular}{|l|l|}
\hline $\begin{array}{l}\text { Table 3: Vegetation class by SCS (1954) and } C_{\boldsymbol{I}} \\
\text { to estimate the total surface roughness } \mathrm{n} \text {. }\end{array}$ \\
\hline Vegetation class by Scs (1954) & $\boldsymbol{C}_{\boldsymbol{I}}$ \\
\hline $\mathrm{A}=$ close grass cover & 10.00 \\
\hline $\mathrm{B}$ & 7.64 \\
\hline $\mathrm{C}$ & 5.60 \\
\hline $\mathrm{D}$ & 4.44 \\
\hline $\mathrm{E}=$ less close grass cover & 2.88 \\
\hline
\end{tabular}

(ii) Damages of the root network:

The root network of the grass cover can be described as a kind of reinforcement for the clay layer. Therefore, it has an important role in the estimation of the erosion resistance against breaking wave impact as well as wave run up and run down. Stanczak et al. (2007) developed an approach to estimate the detachability of the root network:

$$
k_{d, g, p}=\frac{k_{d, p}}{b \cdot R V R^{2}}
$$

where $k_{d, g, p}$ is the detachability coefficient of the revetment $\left[\mathrm{m}^{3} / \mathrm{kPa}\right], k_{d, p}$ is the detachability coefficient of the clay subsoil $\left[\mathrm{m}^{3} / \mathrm{kPa}\right], b$ is a parameter to describe the influence of the roots on the erodibility of the grass [-] and RVR means Root Volume Ratio (percentage of the roots in the soil) [\%].

Vavrina (2011) developed an approach to assess the quality of grass cover by using the procedure of Weißmann (2003), with which the quality of the clay layer can be evaluated:

$$
N=\left(B_{1} \cdot B_{2} \cdot B_{3} \cdot B_{4}\right)^{0.25}
$$

In this equation $B_{1}$ to $B_{4}$ are several evaluation factors which depend on the grass cover factor, on the root density, on the root distribution and on the root intensity. For further explanation concerning the calculation of these factors see Vavrina (2011).

Depending on the quality of the vegetation Liebrand (1999) distinguished classes for estimating sward openness and classes for the ground cover as can be seen in Table 3 and Table 4, whereby sward openness is expressed as the mean surface of the bare areas occurring in the vegetation.

\begin{tabular}{|l|l|l|}
\hline \multicolumn{3}{|l|}{$\begin{array}{l}\text { Table 4: Classes for estimating sward } \\
\text { openness (Liebrand, 1999). }\end{array}$} \\
\hline $\begin{array}{l}\text { Quality } \\
\text { class }\end{array}$ & $\begin{array}{l}\text { Limits } \\
{\left[\mathbf{c m}^{2}\right]}\end{array}$ & Valuation \\
\hline 1 & $0-1$ & excellent \\
\hline 2 & $1-2.5$ & very good \\
\hline 3 & $2.5-5$ & good \\
\hline 4 & $5-7.5$ & moderate \\
\hline 5 & $7.5-10$ & poor \\
\hline 6 & $>10$ & very poor \\
\hline
\end{tabular}

\begin{tabular}{|l|l|l|}
\hline \multicolumn{3}{|l|}{$\begin{array}{l}\text { Table 5: Quality classes for the ground } \\
\text { cover (Liebrand, 1999). }\end{array}$} \\
\hline $\begin{array}{l}\text { Quality } \\
\text { class }\end{array}$ & Limits & Valuation \\
\hline 1 & $>90 \%$ & excellent \\
\hline 2 & $75-90 \%$ & very good \\
\hline 3 & $60-75 \%$ & good \\
\hline 4 & $45-60 \%$ & moderate \\
\hline 5 & $30-45 \%$ & poor \\
\hline 6 & $<30$ & very poor \\
\hline
\end{tabular}


Young (2005) developed a procedure to model the sliding stability of grass cover, but it does not take into account the influence of holes/damages in the grass cover.

From the FLOODsite project, Buijs (2008) published a report with results of the qualitative and quantitative analysis of holes in embankment whereby it could be seen that damages in the grass cover have less influence on the slope stability of a dike which is comparable to the aforementioned results of the ComCoast project (see Figure 5).

Therefore, Buijs (2008) investigated animal burrows on the inner and outer slope of a dike by means of a 2D-Model in the software program "MStab". It is given that the failure probability increases with the length and depth of the burrow whereas the probability of slope instability of the outside slope increased much more than for the inside slope.

Furthermore, Buijs (2008) suggested that the most critical location of grass turf holes is around the water level on the outside slope of a dike where wave run-up velocities have highest values. A limit state equation for the failure mechanism "grass-stripping on the inner slope" with consideration of grass turf holes was developed as given in the following formula:

$$
Z=\sigma_{t}+\sigma_{\text {root }}+\sigma_{\text {soil }}-\frac{M_{\tau}+M_{\text {hyd }}+M_{\text {soil }, \text { hole }}-M_{\text {soil }, \text { edge }}}{\frac{1}{6} w_{g}\left(h_{-} a\right)^{2}}
$$

where $\sigma_{t}$ is the tensile strength of the soil $\left[\mathrm{kN} / \mathrm{m}^{2}\right], \sigma_{\text {root }}$ is the tensile strength of the roots as a function of the depth underneath the ground surface $\left[\mathrm{kN} / \mathrm{m}^{2}\right], \sigma_{\text {soil }}$ is the pressure exerted by the weight of the soil vertical to the slope $\left[\mathrm{kN} / \mathrm{m}^{2}\right], M_{\tau}$ is the moment of the shear stress $[\mathrm{kNm}], M_{h y d}$ is the moment of the hydrostatic pressure inside the hole $[\mathrm{kNm}], M_{\text {soil,hole }}$ is the moment of the soil pressure inside the hole $[\mathrm{kNm}], M_{\text {soil,edge }}$ is the moment of the soil pressure along the full height of the hole $[\mathrm{kNm}]$ and $h \_a$ is the distance over which the flow shear stress and pressure is distributed [m].

\section{Previous studies on pre-existing damages for quay walls}

As aforementioned, pre-existing damages for dikes are focusing on holes in the grass cover and the resulting erosion of the clay layer. However, quay walls are much more complex structures as they consist of an anchored sheet pile wall made of steel integrated in a reinforced concrete superstructure. Therefore, several failure mechanisms exist and most of pre-existing damages are related to corrosion of sheet pile wall as well as the reinforced steel and failure of the concrete superstructure as already explained before. Figure 7 gives an overview of typical damages at a quay wall developed by Horstmann (2010).

By analysing of totally 227 damages at several quay walls, Horstmann (2010) found out that 69 damages belongs to the superstructure and 59 damages to the sheet pile wall so that these two categories have the major part with $59 \%$ of the total amount of damages. Corrosion of steel and reinforced elements leads to a reduction of the load capacity and therefore to insufficient strength of the supporting components of a quay wall which can lead again to tilting or shifting of the structure.

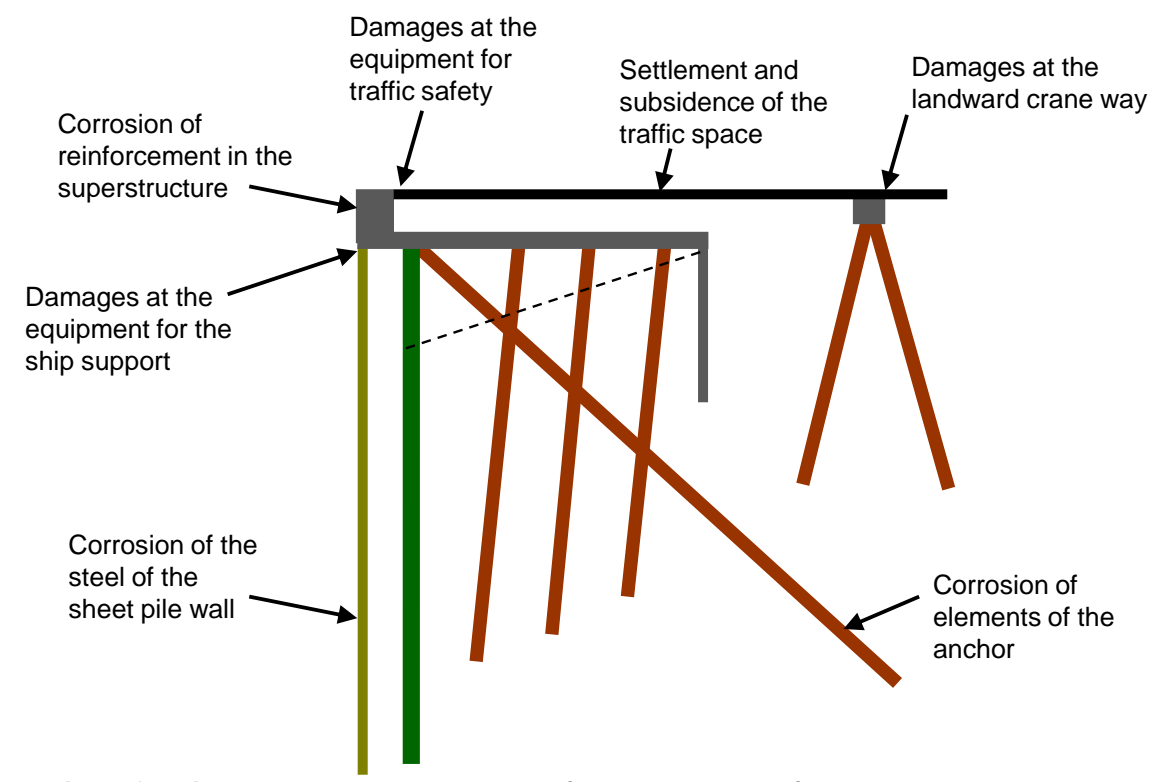

Figure 7: Overview of typical damages at a quay wall (Horstmann, 2010). 
With the results of the FLOODsite project, Allsop et al. (2007) published a report considering failure mechanisms for flood defence structures in which limit state equations for the following failure mechanisms for quay walls are given:

- Overturning failure of wall element, insufficient strength of tie rod

- Overturning failure of wall element, insufficient strength of soil at anchor

- Failure of sheet pile wall element in bending

- $\quad$ Rotation failure of sheet pile wall after loss of tie road

At the end of this paper an example will be given by considering the failure mechanism of insufficient strength of the tie rod.

\section{PRINCIPLES OF THE MIM STRATEGY}

Despite the importance of sea and estuary dikes for the protection of the hinterland as well as quay walls for port companies, there is currently no coherent and systematic strategy for their monitoring, inspection and maintenance. Especially, the risk associated with the residual strength of German sea dikes and quay walls should be considered and determined in the same way.

Therefore, the MIM strategy is integrated as a key component into a framework for life cycle engineering of coastal structures as an approach to quantify and evaluate risk, and finally to manage the remaining risk (see Figure 8).

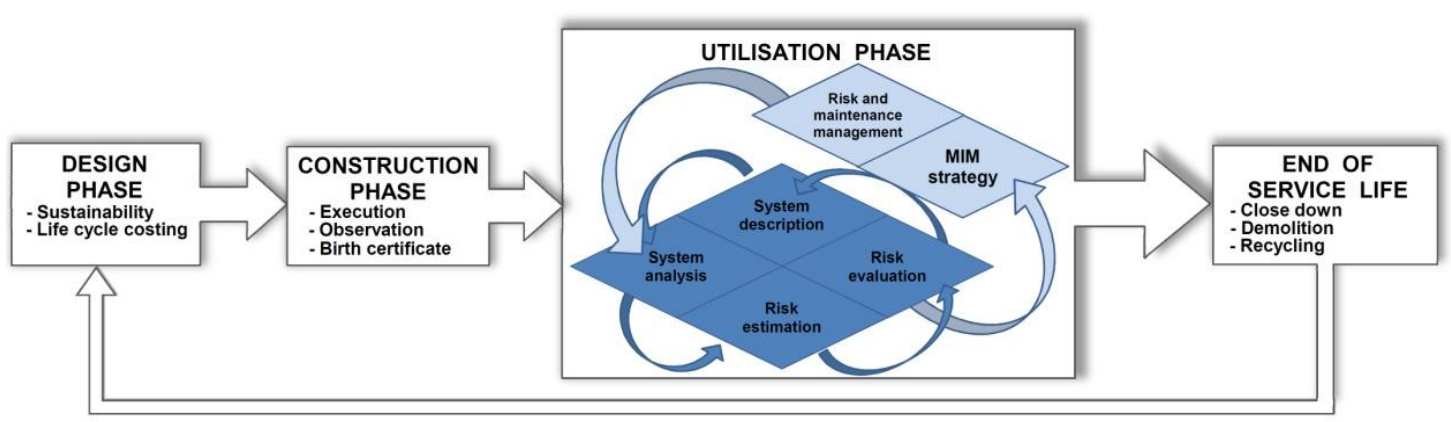

Figure 8. Life cycle phases including monitoring, inspection and maintenance (MIM) strategy (Horstmann et al., 2012).

Every structure, e.g. sea and estuary dikes as well as quay walls, undergoes certain steps throughout its lifetime. In the design phase of a structure, both sustainability and life-cycle-costing should be considered.

In the construction phase, it is important to collect information and parameters of the execution and observation of the erection process to generate a birth-certificate which is necessary as input data set for the MIM-strategy.

After the design phase of the structure (e.g. dike, quay wall) and the ensuing construction phase, the longest-lasting time period named utilisation phase follows, to which the MIM strategy is applied. This phase is subdivided in the steps "system description", "system analysis", "risk estimation" and "risk evaluation", and the subsequent MIM strategy with the methodology for risk and maintenance management. These steps will be described in detail in the following sections.

\section{Step 1: System description}

Initially, stakeholders or owners of dikes and quay walls have to analyze their dike systems and quay wall structures and to specify the stresses and resistance of the total structure as can be seen in the flowchart with the individual work stage in the left side of Figure 9. For this purpose, a classification of the total structure in subsystems, components and elements as suggested by Krishnasamy et al. (2005) and Schieß1 (2007) has to be performed.

For instance, subsystems represent different construction phases of the dike and the quay wall; components are the seaward and landward slope and the dike core or, in case of a quay wall, the sheet pile wall, tension piles and anchorage, the superstructure and the pavement. These components can subdivided further in elements of a dike such as sand core, clay layer and grass cover or different special parts of the dike (e.g. toe protection). In the case of a quay wall the component 'anchorage' can be divided e.g. in anchor wall, tension pile and connection elements. The classification of the total system in subsystems, components and elements for quay walls can be done by considering different exposure classes for concrete as shown in Table 1. 


\begin{tabular}{|c|c|c|c|}
\hline \multirow{7}{*}{$\begin{array}{ll}\text { (2) (3) } & (3) \\
\text { (1) } & (4)-1\end{array}$} & \multicolumn{2}{|c|}{ Reinforced concrete area } & Exposure classes \\
\hline & \multirow[t]{2}{*}{ Superstructure } & (1) & XC4; XS3; XF2; XA2; XM1 \\
\hline & & (2) & XC4; XD3; XS3; XF2; XA2; XM1 \\
\hline & Traffic space & (3) & $\begin{array}{l}\text { XC4; XD3; XS3; XF2; XA2; XM2; } \\
\text { XM3 }\end{array}$ \\
\hline & Slab, bottom side & (4) & XC2; XC4; XS3; XF4; XA2 \\
\hline & Slab, upper side & (5) & XC2; XA2 \\
\hline & Piles, crane way & (6) & $\mathrm{XC2} ; \mathrm{XA2}$ \\
\hline
\end{tabular}

For the entire system as well as for each subsystem, component and element, the properties and functions have to be identified. This information has to be saved as an input for the next stage.

\section{Step 2: System analysis}

In this step, interactions of the aforementioned subsystems, components and elements have to be defined as can be seen in the right side of Figure 9 by the individual given work stages.
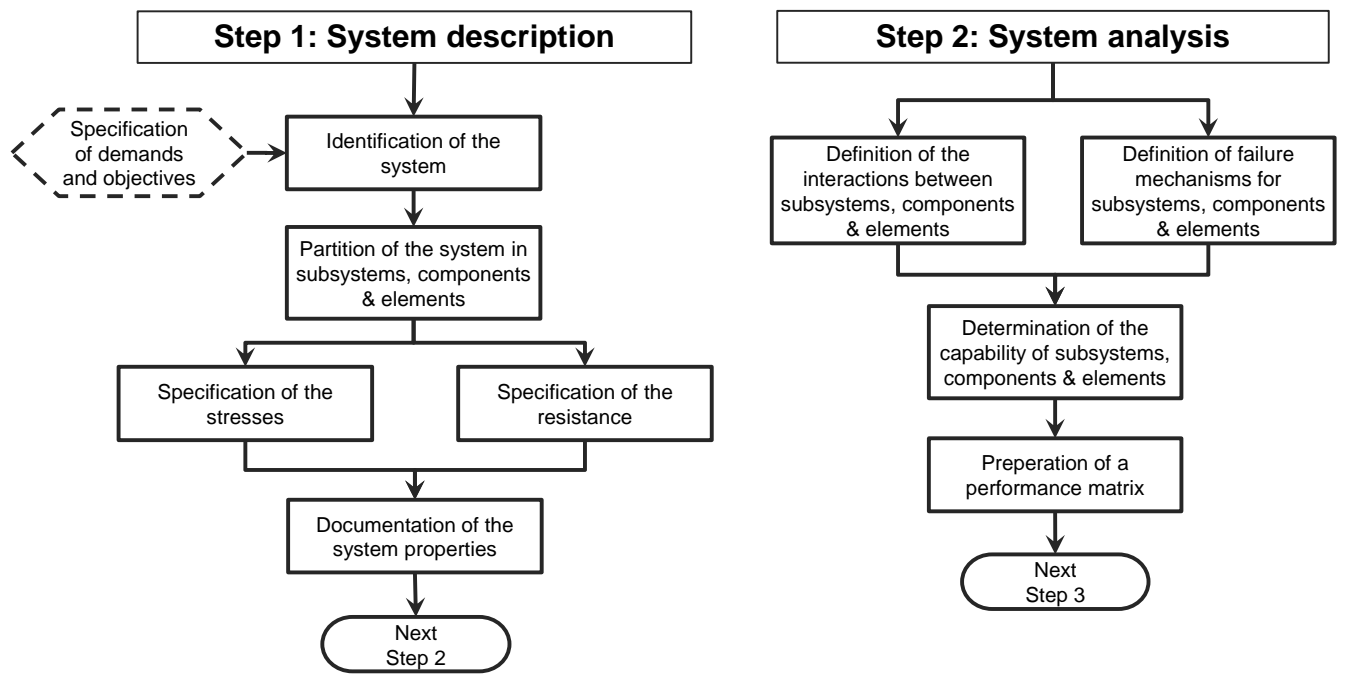

Figure 9. Flowchart of Step 1 (left) and Step 2 (right) (Horstmann et al., 2012).

Additionally, degradation and deterioration mechanisms have to be analyzed based on experience. This information is used as a basis to develop a performance matrix for the structure given by Takahashi et al. (2001) in which for each condition (serviceability, reparability, sustainability, collapse) and for every failure mechanism threshold values are defined. As an example proposed damage criteria for sheet pile quay walls developed by PIANC (2001) are shown in Table 2.

\begin{tabular}{|l|l|l|l|}
\hline \multicolumn{4}{|l|}{ Table 2. Proposed damage criteria for sheet pile quay walls by PIANC (2001). } \\
\hline Level of damage & $\begin{array}{l}\text { Residual } \\
\text { displacement }\end{array}$ & $\begin{array}{l}\text { Residual tilting } \\
\text { towards the sea }\end{array}$ & $\begin{array}{l}\text { Differential } \\
\text { settlement on apron }\end{array}$ \\
\hline I: Serviceability & $<1.5 \%$ & $<3^{\circ}$ & $0.03-0.1 \mathrm{~m}$ \\
\hline II: Reparability & N/A & N/A & N/A \\
\hline III: Load capacity & N/A & N/A & N/A \\
\hline
\end{tabular}

\section{Step 3: Risk estimation}

For each failure mechanism and deterioration, limit state equations have to be developed as indicated in Figure 10, left side. With the implementation of these limit state equations in a fault tree analyses and by performing a reliability analysis the overall probability of a dike failure $P_{f}$ can be calculated. Additionally, damage scenarios for the failure have to be established and the areas which would be affected by the failure have to be evaluated. A vulnerability analysis has then to be performed in which the consequences $E(D)$ of this failure can be calculated. By multiplying the total failure probability $P_{f}$ with the consequences of failure $E(D)$, the risk $R$ is obtainable by using Equation 1 . 


\section{Step 4: Risk analysis}

Next, it is necessary to compare this calculated risk $R$ with acceptable risk criteria $R_{a c c}$ (Oumeraci, 2004). As is given in the right side of Figure 10, aspects regarding personally, socially, economically and ecologically accepted level of risk are given e.g. by Vrijling (1984) or Kuijper \& Vrijling (1998).
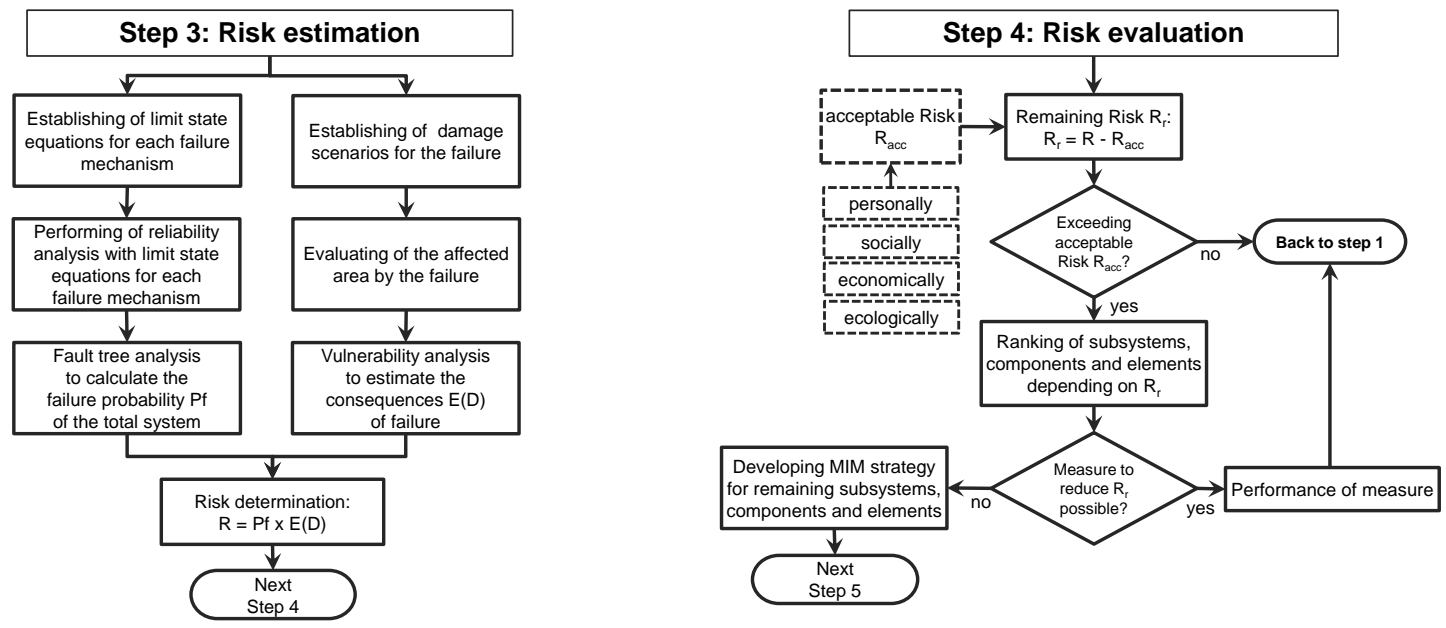

Figure 10. Flowchart of Step 3 (left) and Step 4 (right) (Horstmann et al., 2012).

The remaining risk $R_{r}$ is obtained from the subtraction of the calculated risk $R$ and the acceptable risk $R_{a c c}$. The results of a comparative analysis of the calculated risk $R$ with the risk accepted by stakeholders and owners of a dike or quay wall structure $R_{a c c}$ enable to set priorities for counter measures by ranking those subsystems, components and elements which exceed the acceptable risk $R_{a c c}$. If the measures to reduce the remaining risk $R_{r}$ are appropriate and implemented, then those subsystems, components and elements are updated and the risk $R$ has to be calculated again in step 1 to step 4. And if the measures are not feasible, the MIM strategy has to be adapted to the remaining subsystems, components and elements.

\section{Step 5: Monitoring strategy}

It is essential to treat the remaining risk $R_{r}$ in the ensuing MIM strategy with e.g. monitoring measures until a threshold value is reached which cannot be exceeded without any damage as is given in the left side of Figure 11. Stakeholders and owners have then to decide whether the performance of maintenance and repair measures is possible or if subsystems, components and elements should be treated in the ensuing maintenance strategy in which an inverse fault tree analysis has to be performed in the next step 6.

\section{Step 6: Maintenance strategy}

By setting a target failure probability $P_{f, S}^{t}$ for the total system which is determined on the basis of the acceptable risk criteria $R_{a c c}$ as a top event in the fault tree it is possible to calculate the roots of the fault tree, i.e. the failure probability $P_{f}^{t}$ of each failure mechanism (see Figure 11, right).

With these results one can estimate the residual strength of the components and elements by using the aforementioned limit state equations. Stakeholders and owners of a structure will then have to make a decision about minimum degradation threshold values of each component and element.

In a study by Hijum (1998), damage patterns and limits, failure limits and ultimate failure mechanisms for different condition parameters for a case study of the "Hondsbossche Seadike" are given. Also an application of a maintenance control system and safety assessment is briefly pointed out. 
By comparing the calculated residual strength of components and elements with warning and action thresholds stakeholders and owners of a structure are able to determine the time when those thresholds will be reached. This method gives an opportunity to split time period in intervals for maintenance and inspection efforts.

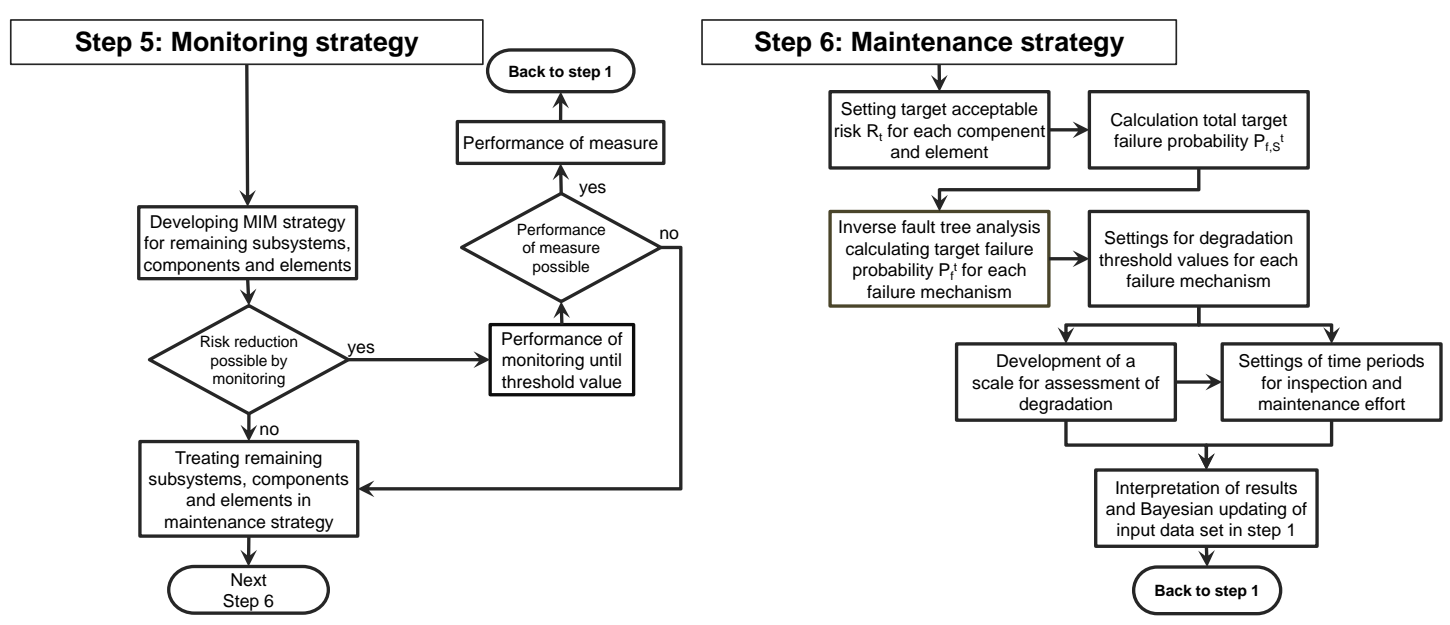

Figure 11. Flowchart of Step 5 (left) and Step 6 (right) (Horstmann et al., 2012).

The procedure described in steps 1 to 6 with risk and maintenance management constitutes an iterative process. This means that after the last step the whole strategy will be updated from the beginning by new data provided by inspection and maintenance reports.

Hence, stakeholders do not always deal with perfect dike structures. Damages or pre-existing damages detected by inspection work have to be integrated in the calculation of failure probabilities. Therefore, in the following an example application for quay walls will be given in order to demonstrate the procedure of step 6 as explained before to estimate the remaining service life of a structure.

\section{EXAMPLE APPLICATION FOR A QUAY WALL}

In order to enable a better understanding of the procedure illustrated in step 6 a brief example for calculating the remaining service life of an element is given by applying the failure mechanism "Overturning failure of wall element, insufficient strength of tie rod".

Photos on the left side of Figure 12 show results from an inspection at a quay wall in a harbor in the northern part of Germany and in the right part of Figure 12 a principle sketch of a quay wall with the location of the corrosion of the tie rod is given.
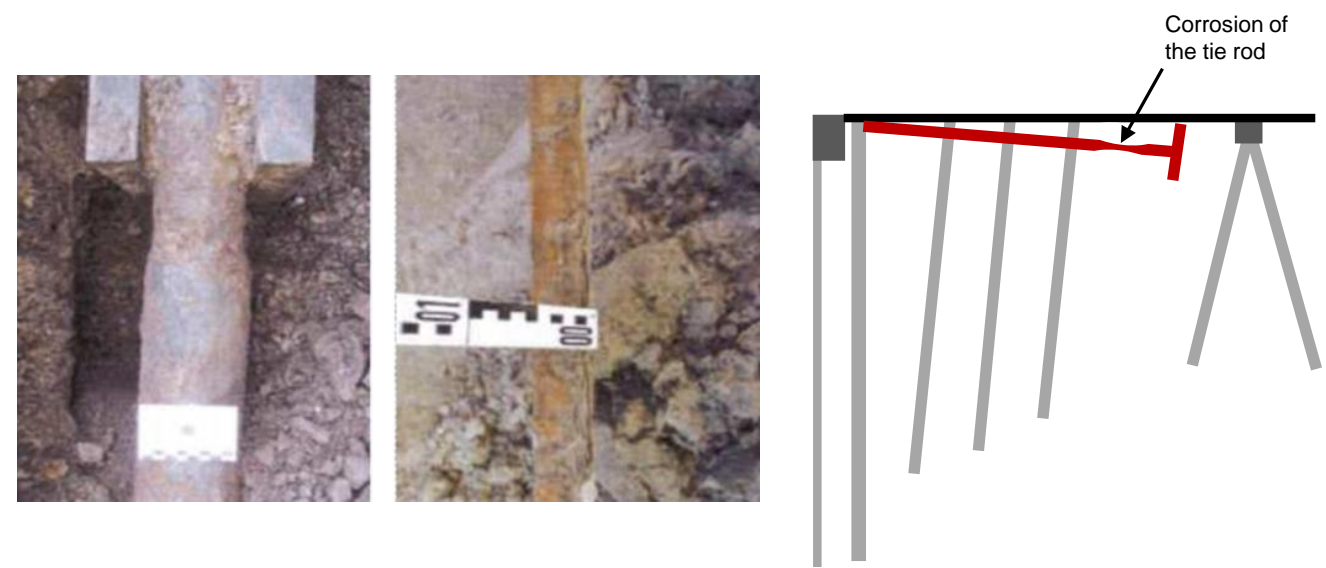

Figure 12. Photos of tie rod corrosion at a quay wall in a harbour of north Germany (left) and principle sketch of the location of the corrosion (right). 
The limit state equation for the aforementioned failure mechanism "Overturning failure of wall element, insufficient strength of tie rod" can be expressed by (see Allsop et al., 2007):

$$
z=R-S=m_{1} F_{u}-m_{2} F_{t o t}
$$

where $F_{u}$ is the tensile force capacity of the tie $\operatorname{rod}[\mathrm{kN}], F_{t o t}$ is the total occurring force in the tie $\operatorname{rod}[\mathrm{kN}]$ and $m_{1}, m_{2}$ are factors which take the model uncertainty into account. The forces $F_{u}$ and $F_{t o t}$ can furthermore be calculated with the following equations:

$$
\begin{aligned}
& F_{\text {tot }}=H_{5} \cdot \frac{w_{a}}{\cos \alpha} \\
& F_{u}=A_{s} \cdot f_{s}
\end{aligned}
$$

where $H_{5}$ considers the resulting earth pressure $[\mathrm{kN} / \mathrm{m}]$ as can be seen in Figure $13, w_{a}$ is the distance between two tie rods, $\alpha$ is the inclination of the tie $\operatorname{rod}\left[{ }^{\circ}\right], A_{s}$ is the total area of the tie $\operatorname{rod}\left[\mathrm{m}^{2}\right]$ and $f_{s}$ is the yield stress of the steel $\left[\mathrm{kN} / \mathrm{m}^{2}\right]$.

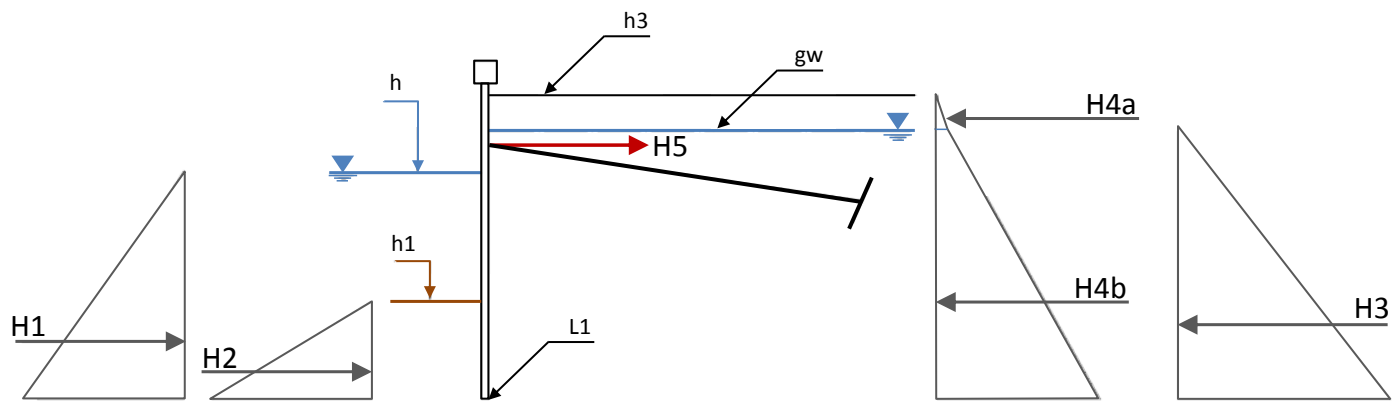

Figure 13. Principle sketch of failure mechanism "Overturning failure of wall element, insufficient strength of tie rod" (Allsop et al., 2007).

Regarding the aforementioned equations 12 to 14 , it is obvious that the load capacity of the tie rod

\begin{tabular}{|c|c|}
\hline Description & Value \\
\hline Age of the quay wall & 30 years \\
\hline $\begin{array}{l}\text { Total area } A_{s} \text { of the tie rod } \\
\text { (initial stage) }\end{array}$ & $3,848 \mathrm{~mm}^{2}$ \\
\hline $\begin{array}{l}\text { Total area } A_{s} \text { of the tie rod (after } \\
30 \text { years }\end{array}$ & $2,827 \mathrm{~mm}^{2}$ \\
\hline Type of steel & S 355 \\
\hline \multicolumn{2}{|l|}{$\begin{array}{l}\text { Statistical parameter of the yield } \\
\text { stress of the steel (DIN 18800) }\end{array}$} \\
\hline Mean value $\mu_{y}$ & $384 \mathrm{~N} / \mathrm{mm}^{2}$ \\
\hline Standard deviation $\sigma_{y}$ & $30.1 \mathrm{~N} / \mathrm{mm}^{2}$ \\
\hline \multicolumn{2}{|l|}{$\begin{array}{l}\text { Statistical parameters of the } \\
\text { dead load }\end{array}$} \\
\hline Mean value $\mu_{G}$ & $850 \mathrm{kN}$ \\
\hline Standard deviation $\sigma_{G}$ & $90 \mathrm{kN}$ \\
\hline
\end{tabular}
depends on the total area $A_{s}$. For the example, necessary parameters of the quay wall are given in Table 6, whereby the statistical parameters for the resistance and the stresses are normal distributed.

The calculation of the remaining service life of the tie rod and therefore the estimation of inspection periods is divided in several stages. Firstly, the failure probability $P_{f}$ of the new tie rod with a diameter of $70 \mathrm{~mm}$ has to be calculated whereby $P_{f}$ can be obtained by Equation 4 . The reliability index $\beta$ can be calculated by using Equation 3 for which the stresses $S$ and resistance $R$ have to be calculated as shown in the following:

Stresses $S$ :

$$
\begin{aligned}
& \mu_{x 1}=\mu_{G}=850 \mathrm{kN} \\
& \sigma_{x 1}=\sigma_{G}=90 \mathrm{kN}
\end{aligned}
$$


Resistance $R$ :

$$
\begin{aligned}
& \mu_{x 2}=\mu_{y} \cdot A_{s}=1478 \mathrm{kN} \\
& \sigma_{x 2}=\sigma_{y} \cdot A_{s}=116 \mathrm{kN}
\end{aligned}
$$

According to Equation 3 and with the results of Equation 15 to 18 the reliability index $\beta$ arises to:

$$
\beta=\frac{1478-850}{\sqrt{90^{2}+116^{2}}}=4.28
$$

Values of the cumulative distribution function (CDF) are listed in tables such as e.g. in Nowak and Collins (2000) and therefore the failure probability $P_{f}$ of the new tie rod follows to:

$$
P_{f}=\phi(-4.28)=9.34 \cdot 10^{-6} / a
$$

After 30 years utilisation phase of the quay wall, degradation of the tie rod could be observed after an inspection. As can roughly be seen from the photos given in Figure 12, the tie rod corroded of approximately $1 \mathrm{~cm}$ and therefore the total area $A_{s}$ given in Table 6 decreased. Applying the Equations 14, 17 and 18 and assuming that the stresses are the same as in the beginning of the utilisation phase the failure probability $P_{f}$ of the 30 years old tie rod arises to:

$$
P_{f}=\phi(-1.91)=2.81 \cdot 10^{-2} / a
$$

CUR (2005) suggested for quay walls the safety category 2 for which is given in the Dutch standards for structures and geotechnology in NEN 6700/6702 a reliability index $\beta$ of 1.8 after 50 years utilisation. Assuming that also the components of the anchor should not degrade more than $\beta=1.8$ an inverse fault tree analysis can be performed to calculate the target failure probability of the tie rod.

Using the exponential distribution in order to predict the degradation of the tie rod the probability density function arises as follows:

$$
f(t)=\lambda e^{-\lambda t}
$$

where $\lambda$ is the failure rate and can be calculated by the following equation:

$$
\lambda=-\frac{d}{d t} \ln (1-F(t))
$$

In this equation $P_{f}$ is the failure probability given in equation (21) with the consideration of the inspection results. Therefore, the failure rate $\lambda$ arises to:

$$
\lambda=-\frac{1}{8760 h / a} \cdot \ln \left(1-2.81 \cdot 10^{-2} / a\right)=3.26 \cdot 10^{-6} / h
$$

By converting equation (22) and applying the target failure probability of $P_{f}^{t}=3.59 \cdot 10^{-2}(\beta=1.8)$ as mentioned before, the remaining time can be calculated until $P_{f}^{t}$ will be reached as given in the following:

$$
T=-\frac{\ln \left(1-P_{f}^{t}\right)}{\lambda}=-\frac{\ln \left(1-3.59 \cdot 10^{-2} / a\right)}{3.26 \cdot 10^{-6} / h \cdot 24 h / d}=468 d=1.28 a
$$

In this example, the remaining service life of the tie rod is approximately 1.28 years as given in Equation 25. With this information stakeholders of a quay wall are able to estimate the overall service life of the total quay wall structure and to develop maintenance and inspection plans for each element, component and subsystem of the entire quay wall.

\section{SUMMARY AND OUTLOOK}

The challenges associated with the sustainable design of coastal structures and the considerable uncertainties associated with climate changes und socio-economic developments necessarily require robustness and flexibility over the entire structure life time. In order to account for the changes which occur over the lifetime of a structure, a risk-based strategy (MIM strategy) is proposed as a key component of an overall framework for life cycle engineering and management. The proposed approach is intended to be applied iteratively during the utilisation phase of the structure. The MIM strategy can also be used as an integral part of a risk-based design of coastal structures as suggested by Oumeraci (2004). 
Therefore, that sea and estuary dikes as well as quay walls degrade over the service life preexisting damages to these structures have to be integrated to the approach of the MIM strategy. The main damages that occur at these structures are explained in this paper.

The principles of the MIM strategy are outlined by describing the six steps of the procedure and an exemplary application for quay walls is provided to illustrate the possibility to estimating residual service life of the structure. Moreover, it is also shown how pre-existing damages will affect and change the failure probability of a structure.

Among the most important challenges, the development of additional time dependent limit state equations for the failure mechanisms as well as time dependent fault trees are noteworthy in order to incorporate this knowledge in the procedure of the MIM strategy. Moreover, much more research on dikes is necessary to investigate the influence of pre-existing damages on the overall dike failure. This knowledge is essential for the prediction of possible changes in the failure probability of a dike.

\section{ACKNOWLEDGMENTS}

The risk-based strategy for monitoring, inspection and maintenance (MIM strategy) for coastal protection and harbour structures is part of the NTH Top-Down Cooperative Project: "Life Cycle Engineering for Engineering Structures and Buildings - Strategies and Methods" which is a joint research project of Leibniz Universität Hannover (LUH) and Technische Universität Braunschweig (TU BS), Germany, and funded by the German Federal State Lower Saxony.

\section{REFERENCES}

Akkerman, G. J.; van Gerven, K. A. J.; Schaap, H. A.; van der Meer, J. W. 2007. Workpackage 3: Development of Alternative Overtopping-resistant Sea defences - Phase 3: Wave overtopping erosion tests at Groningen Sea Dyke. ComCoast. Final Report. Delft. The Netherlands.

Allsop, W.; Kortenhaus. A.; Morris, M. 2007. Failure mechanisms for flood defence structures. Project FLOODsite 2002-2006. Report T04-06-01.

Bakker, W.T.; Vrijling, J.K. 1980. Probabilistic design of sea defences. Proceedings 17th International Conference Coastal Engineering (ICCE), Sydney, 23-28 March 1980: 2040-2059. ASCE.

Buijs, F. 2008. Qualitative and quantitative reliability analysis of holes in embankments. Project FLOODsite 2002-2006. Report T04-09-02.

CUR. 2005. Handbook of quay walls. Taylor \& Francis Group. Balkema. Rotterdam.

CUR 166. 1997. Damwandconstructies. CUR-publicatie 166. Gouda. The Netherlands.

DIN 18800. Stahlbauten - Teil 1: Bemessung und Konstruktion. Beuth Verlag. Germany (in german).

Hijum, v. E. 1998. Aspects of execution and management. In K. W. Pilarczyk (ed), Dikes and Revetments - Design, Maintenance and Safety Assessment. Balkema. Rotterdam. pp 489-522.

Horstmann, N. 2010. Konzeptionelle Entwicklung von Ansätzen für ein Lebensdauermanagementsystem von Hafeninfrastrukturen. Diploma thesis. Franzius-Institute for Hydraulic, Waterways and Coastal Engineering. Leibniz University of Hannover. Germany. (in german, unpublished).

Horstmann, N.; Schimmels S.; Oumeraci, H. 2012. A risk-based strategy for monitoring, inspection and maintenance of coastal protection structures as an integral part of life cycle calculation and optimization processes. State-of-the-Art report. Coastal Research Center, Joint Central Institution of the Leibniz Universität Hannover and the Technische Universität Braunschweig, Germany (in preparation).

Kortenhaus, A. 2003. Probabilistische Methoden für Nordseedeiche. Ph.D. thesis. Leichtweiß-Institute for Hydraulic Engineering and Water Resources. Braunschweig. Germany (in German).

Krishnasamy et al. 2005. Development of a risk-based maintenance (RBM) strategy for a powergenerating plant. Journal of Loss Prevention in the Process Industries. Guildford. Butterworth. pp 69-81.

Kuijper, H. \& Vrijling, J.K. 1998. Probabilistic approach and risk analysis. K. W. Pilarczyk (ed). Dikes and Revetments - Design, Maintenance and Safety Assessment. Balkema. .Rotterdam. The Netherlands. pp 443-462.

Naulin, N.; Hinze, K.; Oumeraci, H.; Kortenhaus, A. 2012. Reliability Analysis of Grass-Covered Sea and Estuary Dikes Focusing on Time-Dependent Failure Mechanisms and Failure Modes. State-ofthe-Art report. Leichtweiß-Institute for Hydraulic Engineering and Water Resources. Braunschweig. Germany (in preparation).

NEN 6700. 1990. Technical principles for buildings structures - TGB 1990 - General principles. Delft. The Netherlands. (in dutch).

NEN 6702. 1990. Technical principles for buildings structures - TGB 1990 - Loadings and deformation. Delft. The Netherlands. (in dutch). 
Nowak. A. S. and Collins, K. R. 2000. Reliability of structures. McGraw-Hill Companies. Boston. USA.

Oumeraci, H. 2004. Sustainable coastal flood defences: scientific and modelling challenges towards an integrated risk-based design concept. Keynote lecture. Proc. First IMA International Conference on Flood Risk Assessment. Southend on Sea: IMA. pp 9-24

Oumeraci, H.; Kortenhaus, A.; Allsop, W.; de Groot, M.; Crouch, R.; Vrijling, H.; Voortman, H. 2001. Probabilistic design tools for vertical breakwater. Swets \& Zeitlinger B.V.. Lisse. The Netherlands.

Pianc. 2001. Seismic Design Guidelines for Port Structures. Working Group No. 34 (WG 34) of the Maritime Navigation Commission (InCom). Lisse [u.a.]: Balkema.

Schieß1, P. 2007. Lebensdauermanagementsystem - Teilprojekt A2. In Deutscher Ausschuss für Stahlbeton (ed), Schlussbericht zur ersten Phase des DAfStb/BMBF-Verbundforschungsvorhaben Nachhaltiges Bauen mit Beton. Berlin: Beuth Verlag GmbH. (in German).

Stanczak, G. \& Geisenhainer, P. 2007. Weak spots in grass and clay cover of sea dikes as potential locations of breach initiation. Technical Note. Leichtweiss-Institute for Hydraulic Engineering and

Water Resources. Braunschweig. Germany.

Stanczak, G.; Oumeraci, H. 2012a. Modeling sea dike breaching induced by breaking wave impact laboratory experiments and computational model. Coastal Engineering. Vol. 59. No. 1. Amsterdam. The Netherlands. pp 28-37.

Stanczak, G.; Oumeraci, H. 2012b. Model for prediction of sea dike breaching initiated by breaking wave impact. Journal of Natural Hazards. Vol. 61. No. 2. pp 673-687.

Takahashi et al. 2001. Performance Design for Maritime Structures and Its Application to Vertical Breakwaters - Caisson Sliding and Deformation-Based Reliability Design. Proc. of International Workshop on Advanced Design of Maritime Structures in the 21st century (ADM21), Yokosuka, 5-7 March 2001. PHRI. pp 63-73.

Tuan, T.Q.; Oumeraci, H. 2012. Modelling of wave overtopping-induced erosion of grassed inner seadike slopes. Natural Hazards. Springer (31 March 2012). pp 1-31.

Vrijling, J. K. 1984. Some considerations of an acceptable level of risk in the Netherlands. Technical Advisory Committee for Dykes and Flood Defences - Working Group 10. Delft. The Netherlands. 